\title{
A IGUALDADE DE GÉNERO NAS ORGANIZAÇÕES E O EFEITO DO RECONHECIMENTO PÚBLICO: O CASO DO PRÉMIO IGUALDADE É QUALIDADE
}

\author{
Mariana Pinheiro* \\ (D) https: / / orcid.org/0000-0002-5563-5252 \\ Sara Falcão Casaca \\ (D) https: / / orcid.org/0000-0002-7944-5007
}

\section{Resumo}

Este artigo decorre de uma investigação que abrangeu as organizações distinguidas com o Prémio Igualdade é Qualidade (PIQ). Resulta da compilação, análise e categorização de todas as práticas já reconhecidas, assim como da análise de conteúdo de informação institucional. As conclusões são também sustentadas pela informação resultante de um inquérito por questionário enviado às organizações premiadas. Os resultados sugerem que as práticas reconhecidas como exemplares não estavam plenamente ancoradas numa abordagem integrada de igualdade de género. Conclui-se também que a atribuição do Prémio não tem contribuído para a efetiva institucionalização de políticas, processos e práticas de promoção da igualdade entre mulheres e homens nas organizações distinguidas.

Palavras-chave: Igualdade entre mulheres e homens, boas práticas, gender mainstreaming, Prémio Igualdade é Qualidade.

\section{Abstract \\ Gender Equality in Organisations and the Effect of Public Recognition: The Case of the Equality Is Quality Award \\ This article draws on a research study involving the organisations distinguished with the Equality is Quality Award (PIQ). It results from the compilation, analysis and categori- sation of all the recognised practices, as well as of the analysis of the content of institutional information. Conclusions are also drawn from the data gathered through the questionnaire sent to the awarded organisations. Findings suggest that the practices recognised as exem- plary were not fully embedded in a gender mainstreaming approach. It is also concluded that the award has not contributed to an effective institutionalisation of policies, processes and practices geared towards the promotion of equality between women and men in the awarded-winning organisations.}

Keywords: Equality between women and men, good practices, gender mainstreaming, Equality is Quality award.

ISEG - Lisbon School of Economics \& Management, Universidade de Lisboa.

Endereço eletrónico: marianapinheiro@aln.iseg.ulisboa.pt.

*** ISEG - Lisbon School of Economics \& Management, Universidade de Lisboa; SOCIUS - Centro de Investigação em Sociologia Económica e das Organizações/CSG, 1200-781 Lisboa, Portugal. Endereço postal: ISEG - Lisbon School of Economics \& Management, Universidade de Lisboa, Rua do Quelhas, n. ${ }^{\circ}$ 6, 1200-781 Lisboa, Portugal.

Endereço eletrónico: sarafc@iseg.ulisboa.pt 


\begin{abstract}
Resumen
Igualdad de género en las organizaciones y el efecto del reconocimiento público: el caso del premio igualdad es calidad (PIQ)

Este artículo es el resultado de una investigación que abarcó organizaciones distinguidas con el Premio Igualdad es Calidad (PIQ). Resulta de la compilación, análisis y categorización de todas las prácticas ya reconocidas, así como del análisis del contenido de información institucional. Las conclusiones también son apoyadas por información resultante de un cuestionario enviado a todas las organizaciones ya premiadas. Los resultados obtenidos sugieren que las prácticas distinguidas no estaban respaldadas por un pleno enfoque integrado de igualdad de género. Además, el premio no ha contribuido para la efectiva institucionalización de políticas, procesos y prácticas de promoción de la igualdad entre mujeres y hombres en las organizaciones premiadas.
\end{abstract}

Palabras clave: Igualdad entre mujeres y hombres, buenas prácticas, gender mainstreaming, premio Igualdad es Calidad.

\title{
Introdução
}

A Comissão para a Igualdade no Trabalho e no Emprego (CITE), desde o ano 2000, em conjunto com a Comissão para a Cidadania e a Igualdade de Género (CIG), desde 2009, têm vindo a atribuir o Prémio Igualdade é Qualidade (PIQ). Este tem como objetivo distinguir as entidades empregadoras que, para lá do cumprimento das disposições legais, apresentam políticas e práticas exemplares no domínio da igualdade entre mulheres e homens. O presente artigo decorre de uma investigação que abrangeu as organizações distinguidas com este Prémio, tendo sido guiada por duas questões fundamentais: (1) em que medida as políticas e práticas reconhecidas como exemplares estavam ancoradas numa abordagem integrada de género, estabilizada no quotidiano das organizações; e (2) se o reconhecimento público favoreceu a consolidação de políticas e práticas organizacionais promotoras de uma efetiva igualdade entre mulheres e homens. ${ }^{1}$

Foi privilegiada uma abordagem metodológica mista. Procedeu-se, num primeiro momento, à compilação, análise e categorização de todas as práticas reconhecidas como exemplares, assim como à análise (qualitativa e quantitativa) de conteúdo de informação institucional relativa a todas organizações premiadas (41, no total). Para apreender a existência de políticas e práticas de gestão (e de Gestão de Recursos Humanos) orientadas para a efetivação da igualdade entre mulheres e homens, numa fase seguinte foi enviado um inquérito por questionário a todas as organizações já distinguidas, tendo-se seguidamente procedido à análise estatística dos resultados obtidos.

O estudo insere-se num projeto de investigação mais vasto [Não identificado nesta fase para não comprometer o anonimato]. 
O texto encontra-se estruturado de modo a referenciar (sinteticamente) os contributos teóricos em torno da genderização das organizações, assim como aqueles que têm integrado uma perspetiva de género nas abordagens sobre mudança organizacional. Posteriormente, são explicitadas as opções metodológicas, sendo analisados e discutidos os resultados do estudo. Estes sugerem que as práticas reconhecidas com a atribuição do PIQ não estavam plenamente ancoradas numa abordagem integrada de igualdade de género. Conclui-se também que a atribuição do Prémio não tem contribuído para uma efetiva institucionalização de políticas, processos e práticas de promoção da igualdade entre mulheres e homens, articuladas, coerentes e estabilizadas no quotidiano das organizações.

\section{As organizações como contextos genderizados: contributos teóricos}

As desigualdades entre mulheres e homens nas organizações começaram a ser evidenciadas na década de 1970, enquadrando-se fundamentalmente em estudos feministas atentos à identificação dos processos de discriminação e de segregação sexual nas profissões e nas hierarquias das empresas (Calás, Smircich e Holvino 2014). Como recorda Acker (1990), o movimento feminista da segunda vaga denunciou as hierarquias organizacionais e as práticas burocráticas enquanto estruturas de dominação masculina que contribuíam para a opressão, o controlo e a subalternização das mulheres. A divisão sexual do trabalho nas organizações era, então, fundamentalmente atribuída ao entrosamento entre a estrutura burocrática e a estrutura patriarcal, refletido na masculinidade da autoridade burocrática (Ferguson 1984; Savage e Witz 1993). O debate teórico apresentava-se essencialmente ancorado nas abordagens estruturalistas, salientando a existência de obstáculos organizacionais estruturais e a necessidade de criação de políticas e de medidas capazes de garantir a efetiva igualdade entre mulheres e homens (e.g., Walby 1990; Witz 1997; Ferreira 1999).

A partir da década de 1980, as lentes da análise reorientaram-se para a genderização das estruturas, das práticas, dos processos organizacionais, das profissões e das hierarquias, assim como para a dimensão sexualizada do trabalho e das organizações (e.g., Acker 1990; Cockburn 1991). Deve-se essencialmente a Joan Acker, no início da década de 1990, a fundamentação teórica de que as organizações são genderizadas - i.e., que o género está incrustado nas estruturas, políticas, normas e processos organizacionais e de gestão, nas práticas e nas interações sociais que enformam o quotidiano dos contextos organizacionais. Reconhece-se que os locais de trabalho não são neutros, mas, sim, regimes de género bem definidos - espaços onde se (re) produz a divisão do trabalho entre mulheres e homens e uma estrutura de autoridade e de poder alinhada com o ideal de masculinidade hegemónica (Connell 2006).

Numa linha de pensamento pós-estruturalista, socioconstrutivista e construtivista, várias teses têm discorrido sobre a possibilidade de processos de degenderi- 
zação, geradores de transformação das estruturas e das culturas organizacionais no sentido da superação da dominação masculina. As organizações são, neste âmbito, perspetivadas como construções sociais passíveis de mudança (Bendl 2005). As mulheres e os homens, enquanto agentes ativos em contexto de trabalho, tanto podem (re)produzir as assimetrias como serem estimuladas/os a desafiar as estruturas de dominação e as relações de poder vigentes (Alvesson e Billing 2009; Lewis e Simpson, 2012).

Em síntese, o entrosamento entre contributos estruturalistas e pós-estruturalistas tem favorecido o reconhecimento da complexidade dos obstáculos que se colocam à igualdade entre mulheres e homens, ainda que estes sejam passíveis de questionamento e transformação. No percurso do desenvolvimento do pensamento teórico sobre género e organizações, há a destacar - como faremos seguidamente - a integração de uma perspetiva de género no campo científico sobre mudança organizacional.

\section{A integração de uma perspetiva de género na mudança organizacional}

A literatura gestionária sobre mudança organizacional tem sido relativamente indiferente à relevância de uma perspetiva de género, ou, quando assim não sucede, tende a propor soluções focadas nas mulheres (Fix the Women Approach), como se a situação de desvantagem laboral e profissional decorresse de limitações das mesmas e não de condicionalismos estruturais (Kolb et al. 2003). Deve-se essencialmente aos estudos alicerçados nas abordagens feministas e nos referenciais da igualdade entre mulheres e homens a fundamentação teórica e empírica sobre a importância de uma abordagem integrada de igualdade de género (gender mainstreaming) (Benschop e Verloo 2011).

A estratégia de gender mainstreaming - inicialmente integrada na Plataforma de Ação de Pequim, no contexto da Quarta Conferência Mundial das Nações Unidas sobre as Mulheres, em 1995, retomada e amplamente suportada pelo Conselho de Europa - é definida como a (re)organização, a melhoria, o desenvolvimento e a avaliação dos processos de implementação de políticas para que a perspetiva da igualdade de género seja incorporada em todas as políticas, a todos os níveis e em todas as fases, pelos atores implicados nos processos de tomada de decisão (Conselho da Europa 1998). Se, no plano macro, a integração desta abordagem visa a transformação das estruturas societais, no caso das organizações, deverá potenciar uma mudança estrutural (EIGE 2016) capaz de garantir a igualdade de oportunidades no acesso ao emprego e nas condições de trabalho, a dessegregação horizontal e vertical, a igualdade salarial e a conciliação entre a vida profissional, familiar e pessoal, criando condições de paridade na conformidade das responsabilidades profissionais e familiares (Monteiro e Ferreira 2013; veja-se também Perista et al. 2008; Casaca et al. 2016). 
De acordo com a literatura, a mudança organizacional deve ser enquadrada num processo sistémico e planeado, que passa pela adoção de um método colaborativo e participativo de investigação-ação (Ely e Meyerson 2000; OIT 2012). A integração sistemática, explícita e coerentemente articulada de uma perspetiva de igualdade entre mulheres e homens nas organizações compreende as etapas seguintes: (1) a análise sistemática (diagnóstico) das condições laborais e profissionais das mulheres e dos homens que integram a organização, das suas prioridades, necessidades e expectativas, bem como dos fatores que (direta e/ou indiretamente) condicionam a efetiva igualdade de oportunidades e de tratamento e limitam a igualdade de resultados; (2) a elaboração de planos de ação, visando a (re)organização e a melhoria dos processos de tomada de decisão, das políticas, das práticas e dos processos internos de gestão e de organização do trabalho para assegurar a incorporação transversal, em todas as áreas e a todos os níveis, da igualdade entre homens e mulheres; (3) a criação de uma infraestrutura interna estatutariamente reconhecida (comissão/comité para a igualdade entre mulheres e homens) e a alocação de recursos adequados (técnicos e financeiros); (4) a monitorização sistemática das intervenções e a realização dos ajustamentos necessários; (5) o compromisso político do topo e de todas as pessoas com responsabilidades de gestão e liderança; (5) a participação de todos os membros da organização no diagnóstico e na discussão de resultados; e (6) a capacitação de todas e todos as/os intervenientes para garantir a estabilização e a institucionalização dos novos processos de gestão e de trabalho (Casaca e Lortie 2018).

Entende-se que, além de planeado e sistémico, o processo de mudança deverá ser também gradual e contínuo (Macdonald, Sprenger e Dubel 1997), desenrolando-se a partir de pequenas vitórias (small wins) (Weick e Quinn 1999; Ely e Meyerson 2000), embora sem perder de vista uma agenda mais substantiva e estrutural, necessariamente mais prolongada no tempo (Correll, 2017).

As investigações, todavia, têm demonstrado que os projetos de mudança organizacional orientados para a promoção da igualdade de género dificilmente são verdadeiramente transformadores (Eriksson-Zetterquist e Remark 2016). Tal sucede porque, em geral, as mudanças são fragmentadas e os resultados pouco consistentes (Benschop e Verloo 2011), evidenciando a dimensão estrutural do género e a complexidade de uma agenda para a igualdade de facto entre mulheres e homens (Hearn, 2000). Acresce que muitas organizações tendem a replicar temas em voga e a adotar um discurso «politicamente correto», à revelia de uma estratégia articulada e coerente, suportada por intervenções estruturadas e pela monitorização regular dos resultados (Liff e Cameron 1997). Os estudos evidenciam que, frequentemente, a promoção da igualdade entre mulheres e homens não é priorizada pelas entidades empregadoras, concorrendo com o verdadeiro mainstream: a procura de eficiência e de rentabilidade dos negócios (Benschop e Verloo 2011). A falta de um genuíno empenhamento político das lideranças (a vários níveis da estrutura organizacional) e de envolvimento coletivo tende a gerar focos de resis- 
tência e a comprometer o alcance da mudança (Ely e Meyerson 2000). Falhas na comunicação limitam ou impedem o sentido de urgência (Kotter e Cohen 2002) e a ausência de formação em igualdade entre mulheres e homens e de ações concretas orientadas para a desconstrução de estereótipos de género são também fatores que condicionam (ou travam) o potencial de transformação (Macdonald, Sprenger e Dubel 1997; Casaca e Lortie 2018).

\section{O Prémio Igualdade é Qualidade (PIQ): origem e desenvolvimentos}

A origem do PIQ remonta às orientações delineadas no contexto do Conselho Europeu Extraordinário de Luxemburgo, nos finais de 1990. A Estratégia Europeia para o Emprego assentava em quatro pilares estruturantes (empregabilidade, espírito empresarial, adaptabilidade e igualdade de oportunidades), que deveriam ser desenvolvidos por cada Estado-membro através de um Plano Nacional de Emprego. Com o IV Pilar (Igualdade de Oportunidades), foi possível reforçar a importância da implementação de igualdade de oportunidades entre mulheres e homens, através de vários instrumentos, incluindo a atribuição de prémios a organizações que adotassem políticas exemplares nesse domínio (Rêgo 2012). O Prémio foi instituído em 2000 e visa distinguir empresas e outras entidades empregadoras (públicas, cooperativas, associações e outras sem fins lucrativos) ${ }^{2}$ que se destaquem pelo desenvolvimento e aplicação de políticas e práticas exemplares de igualdade entre mulheres e homens no emprego, na formação profissional, na conciliação entre a vida familiar e profissional, e, mais recentemente, também no domínio da prevenção e combate à violência doméstica e de género.

Tendo inicialmente sido uma iniciativa da CITE, o Prémio é, desde 2009, atribuído conjuntamente com a CIG. É composto por duas versões (Prémio e Menção Honrosa), conta com 12 edições e foram até ao momento distinguidas 41 organizações. O processo inicia-se com um período de candidaturas definido pela CITE e pela CIG, sendo disponibilizado para o efeito um formulário e o regulamento do concurso. A avaliação técnica é elaborada por uma equipa de peritas/os, sendo o resultado apreciado por um júri composto por membros da CITE $^{3}$ e, desde 2009,

2 A partir de 2010 (9. a edição), o PIQ passou a contemplar outras categorias, passando não só a ser atribuído a empresas mas, também, a outras entidades empregadoras do setor público e privado. Já em 2014 (11. a edição) passou também a ser incluída a categoria «setor da economia social». A CITE é composta por um órgão tripartido que integra um/a representante do ministério com atribuições na área do emprego, que preside, um/a representante do ministério com atribuições na área da igualdade, um/a representante do ministério com atribuições na área da Administração Pública, um/a representante do ministério com atribuições na área da solidariedade e da segurança social, dois/duas representantes de cada uma das associações sindicais com assento na Comissão Permanente de Concertação Social (CGTP-IN e UGT) e um/uma representante de cada 
também por um/a representante da CIG. Deve notar-se que, ao longo do tempo, os critérios de avaliação foram sendo progressivamente ajustados para possibilitar o cumprimento por parte de organizações de diferentes dimensões, setores, estatutos e naturezas jurídicas. Além disso, esses critérios têm vindo a refletir novas prioridades políticas; na edição de 2014, por exemplo, passou a ser integrada a dimensão «Prevenção e combate à violência doméstica e de género».

As cinco brochuras do PIQ que estão disponíveis online ${ }^{4}$, referentes às cinco últimas edições (2008/2009, 2010, 2012, 2014 e 2016/2017), contemplam as dimensões da igualdade de género que têm estado sujeitas a avaliação técnica: missão e valores; recrutamento e seleção; aprendizagem e formação contínua; avaliação de desempenho; progressão e desenvolvimento de carreiras; articulação entre a vida profissional, familiar e pessoal; respeito pela dignidade e integridade das pessoas trabalhadoras; diálogo social e participação; e combate à violência doméstica e de género (desde 2014). Estão presentemente definidos 11 objetivos que as organizações devem cumprir (V. Quadro 1). Importa notar que em algumas edições (2010, 2014 e 2016/17) apenas foram atribuídas menções honrosas, assinalando antes o potencial de boas práticas em curso.

\section{Quadro 1.}

Objetivos do PIQ

Combater a segregação profissional entre as mulheres e os homens no mercado de trabalho

Eliminar as desigualdades nos ganhos médios mensais entre as mulheres e os homens

Reduzir o diferencial entre mulheres e homens na sua integração no mercado de trabalho

Melhorar a qualidade das condições de trabalho

Sensibilizar os parceiros sociais para, ao nível da contratação coletiva, instituírem boas práticas

Aumentar a participação equilibrada das mulheres e dos homens no emprego e na formação profissional

Apoiar a empregabilidade das mulheres e dos homens em setores de atividade em que se encontrem sub-representadas/os

(continua na página seguinte)

uma das associações patronais com assento na Comissão Permanente de Concertação Social (CCP, CIP, CAP e CTP). Fonte: http:/ / cite.gov.pt/pt/acite/quemsomos.html [Acesso em 15 de novembro de 2019].

4 http:/ / cite.gov.pt/pt/premioigualdade/entidadespremiadas.html [Acesso em 15 de novembro de 2019]. 
Valorizar competências adquiridas em contexto profissional, familiar e social

Incorporar na cultura das organizações, designadamente das empresas e outras entidades empregadoras, a ideia de que a conciliação entre a vida profissional, familiar e pessoal

Promover a sensibilização das empresas e outras entidades empregadoras para a incorporação dos princípios da igualdade de género e não discriminação e da parentalidade

Prevenir a violência doméstica e de género, enquanto expressão das assimetrias de género nas relações interpessoais

Fonte: Elaboração própria com base em informação consultada em: http: / / cite.gov.pt / pt/ premio igualdade/oquepremio.html [Acesso em 01/09/2019].

\section{Análise e discussão dos resultados}

\section{Nota metodológica}

Procedeu-se, num primeiro momento, à compilação, análise e categorização de todas as práticas reconhecidas como exemplares, assim como à análise (qualitativa e quantitativa) do conteúdo de informação institucional publicada nos sites de todas as organizações premiadas (41, no total). Numa fase seguinte, foi enviado um email às pessoas responsáveis pela Gestão de Recursos Humanos (GRH) de todas as organizações distinguidas, informando sobre o estudo e pedindo a colaboração através do preenchimento de um inquérito por questionário disponibilizado online. Esta opção decorreu do facto de as candidaturas serem normalmente coordenadas pelas pessoas que dirigem os departamentos de Recursos Humanos (ou áreas equivalentes), cabendo-lhes muito frequentemente o acompanhamento das medidas de promoção da igualdade de género. Para potenciar a veracidade das respostas, foi salvaguardado o anonimato da organização respondente. Dada a sensibilidade do tema da investigação, esta foi também a principal razão para a não realização de entrevistas presenciais.

O inquérito por questionário foi estruturado de modo a identificar a existência de uma estratégia para a igualdade entre mulheres e homens, consubstanciada num plano de ação, assim como mapear as políticas, processos e práticas em vigor. A conceção inspirou-se na literatura anteriormente exposta, destacando-se o pressuposto de que a integração efetiva de uma perspetiva de género está orientada para a transformação estrutural, ancorando-se numa estratégia articulada e coerente, refletida em políticas, processos e práticas institucionalizadas e estabilizadas nas organizações premiadas. A análise efetuada procurou, assim, dar resposta às questões orientadoras do estudo: (1) em que medida as políticas e práticas organizacionais distinguidas com o PIQ estavam ancoradas numa abordagem inte- 
grada de género, estabilizadas no quotidiano dessas organizações; e (2) se o reconhecimento público favoreceu a consolidação de políticas e práticas organizacionais promotoras da igualdade entre mulheres e homens.

\section{Caracterização das organizações e das práticas premiadas}

No decurso de 12 edições do PIQ, foram distinguidas 41 organizações (18 prémios e 41 menções honrosas). Em alguns casos, houve organizações que foram distinguidas mais do que uma vez (ver Anexo 1). A esmagadora maioria (33) detém capital privado (lucrativo), três são associações ou cooperativas e cinco são de capital público. As organizações distinguidas operam em ramos diversos, desde as atividades financeiras e seguros, passando pela indústria automóvel, transformadora, gráfica, metalúrgica e metalomecânica, e, ainda, comércio por grosso e a retalho, atividades de saúde humana e apoio social, atividades imobiliárias, atividades de informática e conexas, e transportes e armazenagem.

Analisando as práticas distinguidas, destacam-se fundamentalmente aquelas relacionadas com a articulação entre a vida profissional, familiar e pessoal. Algumas organizações foram também reconhecidas por: utilização de linguagem inclusiva e de imagens não discriminatórias em função do sexo; assunção do compromisso com a igualdade de género enquanto valor fundamental da organização; adoção de medidas de apoio ao recrutamento e seleção de mulheres e de homens para cargos em que o sexo esteja sub-representado; apoio à formação a mulheres que pretendam potenciar as suas competências técnicas, de liderança e de gestão; disponibilização de ações de sensibilização para a igualdade entre mulheres e homens e sobre a conciliação trabalho-família; incentivo do gozo das licenças parentais por parte dos homens, bem como do uso da licença parental inicial partilhada; e adoção de mecanismos de apoio ao combate da violência doméstica.

Constatámos, a partir da análise ao conteúdo dos sites das 41 organizações distinguidas, que mais de um terço (15) são atualmente membros do iGen - Fórum de Organizações para a Igualdade (criado em 2013 e que tem como missão promover uma cultura coletiva de responsabilidade social e justiça, incorporando nas suas estratégias de gestão os princípios da igualdade e não discriminação entre mulheres e homens no mercado de trabalho). ${ }^{5}$ Causou surpresa, porém, o facto de apenas 5 das 41 organizações ( $12 \%$ do total) fazerem referência à igualdade de género na missão e nos valores. Apenas uma organização divulga publicamente $o$ respetivo Plano para a Igualdade entre Mulheres e Homens, e somente seis fazem referência ao facto de terem sido distinguidas com o PIQ.

Fonte: http:/ / forumigen.cite.gov.pt/ (Acesso em 22 de novembro de 2019). 


\section{Caracterização das organizações participantes no estudo}

De um universo de 41 organizações contactadas, obtiveram-se 22 respostas ( $54 \%$ do total) ao inquérito por questionário. Destas, mais de metade $(57 \%)$ é de grande dimensão, empregando mais de 250 trabalhadores/as e tendo um volume de negócios anual superior a 50 milhões de euros. Com um balanço total anual superior a 43 milhões de euros, 33\% e 10\% são entidades empregadoras de média e pequena dimensão, respetivamente. Seis organizações integram o setor empresarial do Estado, duas são da administração pública local, duas são instituições privadas de solidariedade social (IPSS), e 11 são empresas privadas. ${ }^{6}$

Quanto à caracterização do pessoal ao serviço ${ }^{7}, 36 \%$ das 22 organizações respondentes são constituídas por mais homens do que mulheres, sendo que $18 \%$ (4) apresentam uma representação equilibrada de trabalhadores e trabalhadoras. Assim, predominam as organizações $(46 \%)$ com mais mulheres do que homens. Deve destacar-se, no entanto, que cerca de três quartos $(78 \%)$ das organizações apresentam uma maior percentagem de homens em cargos de direção de primeira linha, e apenas $18 \%$ apresentam uma representação equilibrada de mulheres e homens nesses cargos. Quanto ao número de mulheres e homens que ocupam cargos de direção de topo, apenas duas organizações apresentam maior percentagem de mulheres nestes cargos. Em síntese, as organizações representadas na amostra são maioritariamente compostas por trabalhadoras; no entanto, os cargos mais elevados na hierarquia são maioritariamente ocupados por homens.

Efeitos da atribuição do PIQ nas políticas e práticas promotoras da igualdade entre mulheres e homens

Para a esmagadora maioria das organizações, a atribuição do PIQ contribuiu para a consolidação de políticas de gestão e práticas organizacionais promotoras da igualdade entre mulheres e homens (Figura 1). No entanto, tal não sucedeu em cerca de um quinto das mesmas. No mesmo registo, igual proporção não tem em vigor um Plano para a Igualdade entre Mulheres e Homens (PIMH).

Uma organização não respondeu à respetiva questão.

A análise da caracterização do pessoal ao serviço da organização foi feita através de uma avaliação global das respostas dadas pelas organizações, uma vez que foi garantido o anonimato. 


\section{Figura 1.}

Existência de um PIMH e Consequências da atribuição do PIQ

Existe um Plano para a Igualdade entre Mulheres e Homens?

A atribuição do PIQ (seja na sua versão Prémio ou de Menção Honrosa) estimulou a consolidação de políticas de gestão e práticas organizacionais promotoras da igualdade entre mulheres e homens na organização?

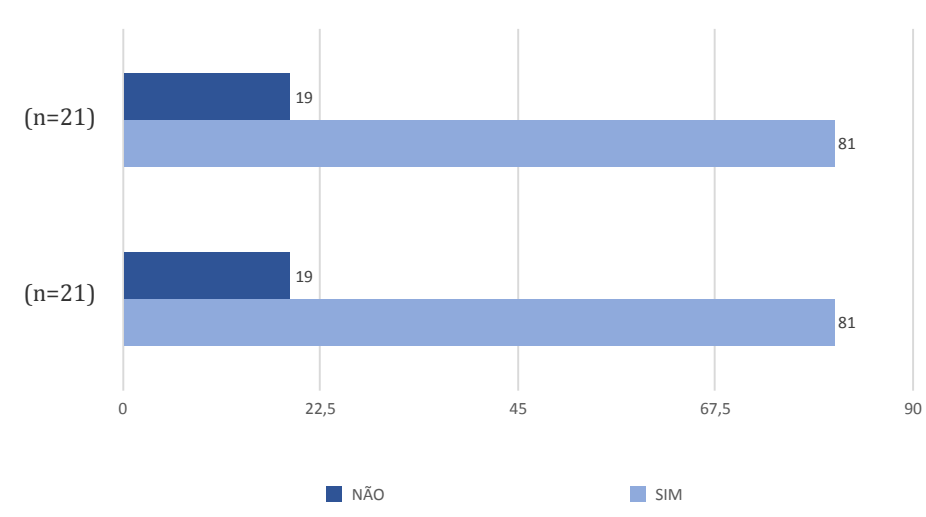

Mais de metade das entidades respondentes não passou a integrar temas associados à igualdade entre mulheres e homens nos planos de formação destinados a trabalhadores e trabalhadoras (Figura 2). Fazendo a ponte com os contributos teóricos sobre a mudança organizacional, trata-se de uma lacuna considerável, uma vez que a capacitação é fundamental para que se efetive a integração de uma perspetiva de género nas políticas e práticas organizacionais (Perista et al. 2008; Monteiro e Ferreira 2013; Casaca et al. 2016; Casaca e Lortie 2018).

\section{Figura 2.}

Integração da Temática «Igualdade entre Mulheres e Homens» nos Planos de Formação

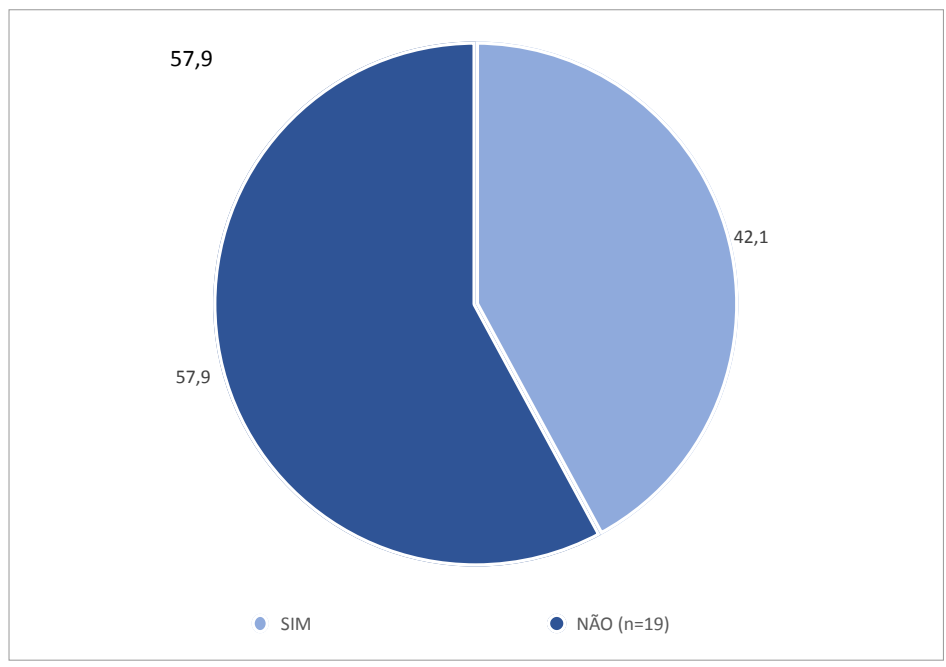


Deve ainda notar-se que em mais de metade das organizações (53\%) não está implementado qualquer procedimento que garanta a prevenção de diferenciais remuneratórios injustificados entre homens e mulheres. Esta constatação não deixa de causar surpresa, uma vez que um dos objetivos do PIQ é a eliminação das desigualdades salariais.

\section{Figura 3.}

Implementação de procedimentos de monitorização dos salários das mulheres e dos homens

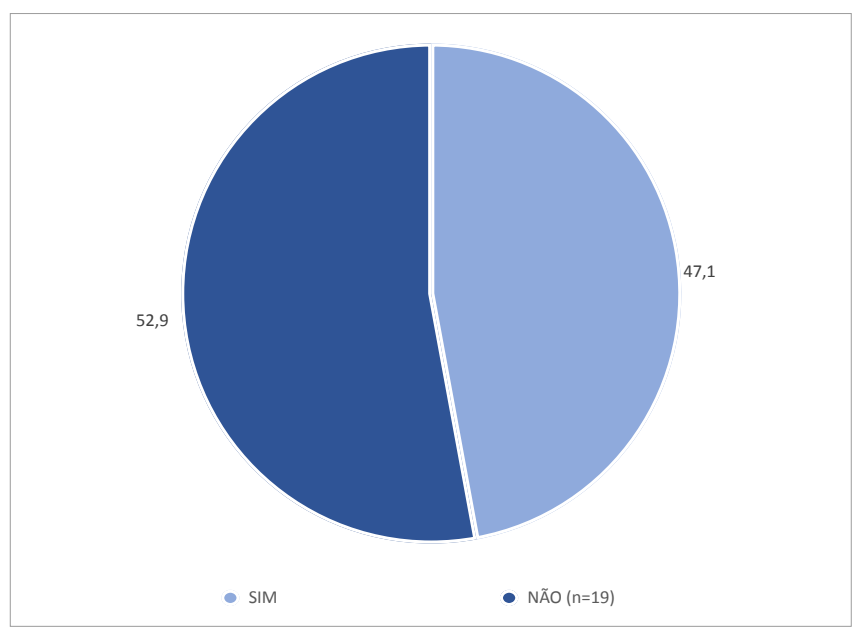

Importa referir que em mais de metade (53\%) das organizações respondentes a atribuição do PIQ não incentivou a adoção de medidas para o acesso de homens e mulheres a profissões/funções onde estejam sub-representados/as (Figura 4). É de assinalar, todavia, que contrariar a segregação sexual profissional é igualmente umas das prioridades do PIQ. No mesmo registo, um número considerável não procedeu à definição de objetivos para alcançar o equilíbrio entre mulheres e homens em cargos de chefia $(44 \%)$ ou de direção de topo $(56 \%)$.

Em aproximadamente três quartos das organizações respondentes estão definidas medidas específicas para facilitar a articulação entre a vida profissional, familiar e pessoal, além do disposto na Lei e/ou nos Instrumentos de Regulamentação Coletiva de Trabalho (Figura 5). É de sublinhar, porém, que em quase metade $(44 \%)$ não existem mecanismos institucionalizados de informação e consulta de trabalhadores e trabalhadoras relacionados com questões de igualdade entre mulheres e homens, articulação entre a vida profissional, familiar e pessoal, e proteção da parentalidade. 
Figura 4.

Existência de medidas para promover homens ou mulheres a cargos de chefia de nível intermédio ou a cargos de direção de topo; Efeito do PIQ na adoção de medidas para o acesso de homens e mulheres a profissões / funções onde estejam sub-representados/as, como consequência da atribuição do PIQ

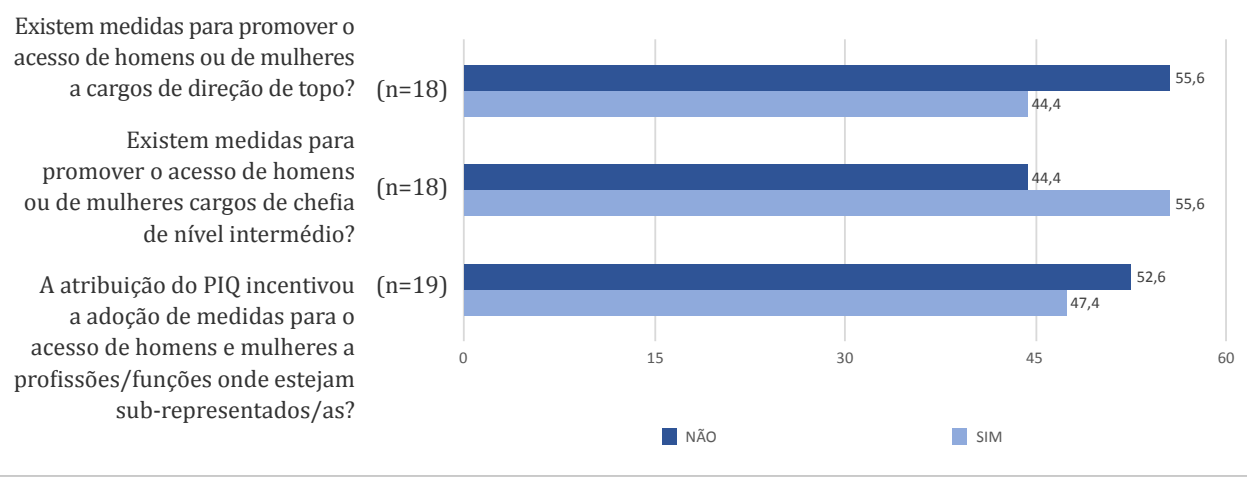

Figura 5.

Implementação de mecanismos institucionalizados de informação e consulta de trabalhadoras e trabalhadores relacionados com questões de igualdade entre mulheres e homens, articulação entre a vida profissional, familiar e pessoal, e proteção da parentalidade;

Medidas facilitadoras da articulação entre a vida profissional, familiar e pessoal

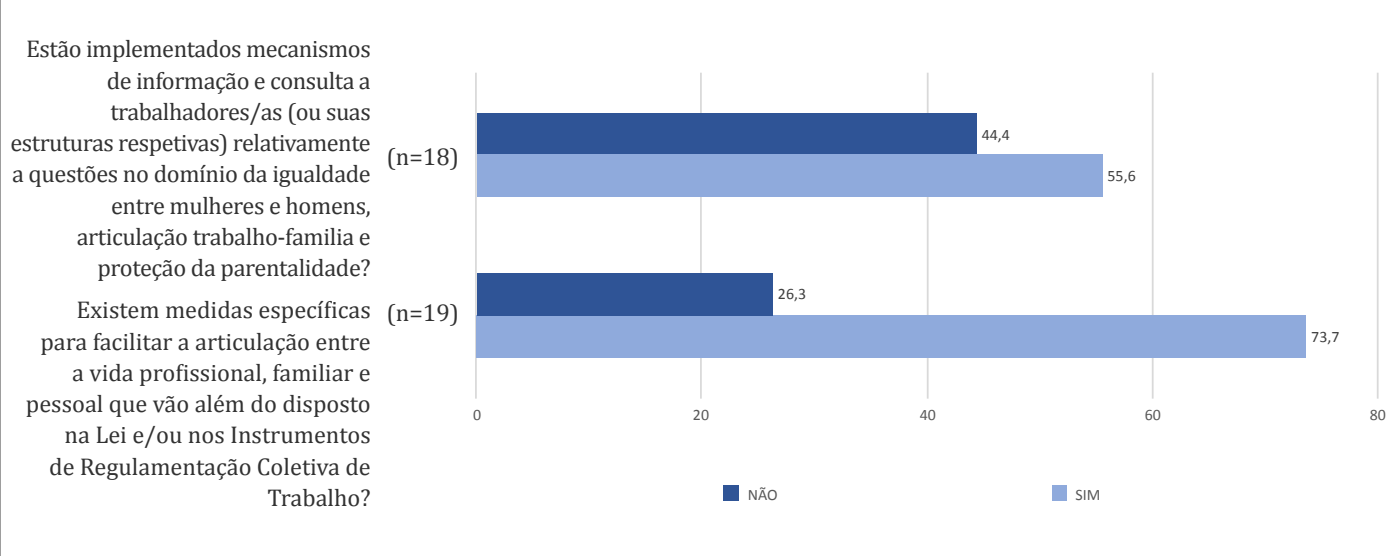

Por fim, constata-se que cerca de um quarto das organizações respondentes ainda não dispõe de procedimentos específicos para a apresentação e apreciação de queixas, não estando igualmente definidas sanções em casos de assédio sexual e/ou moral e de outras formas de violência de género no local de trabalho. 


\section{Figura 6.}

Existência de procedimentos específicos para apresentação e apreciação de queixas e estabelecimento de sanções em casos de assédio sexual e/ ou moral e outras formas de violência de género no local de trabalho

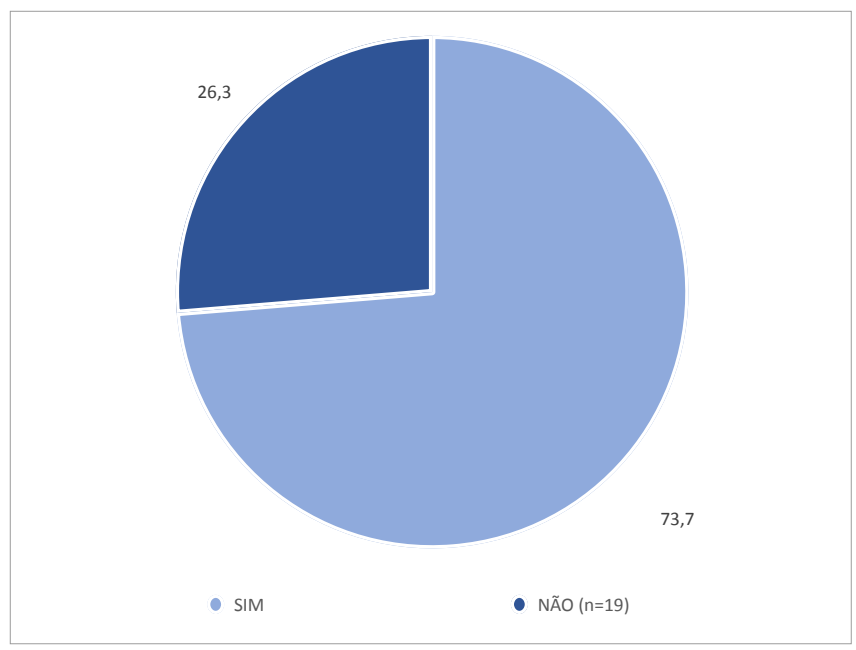

\section{Conclusões e considerações finais}

Foram distinguidas no país, desde o ano 2000, cerca de quatro dezenas de organizações pela adoção de políticas e práticas exemplares em matéria de igualdade entre mulheres e homens. A partir da análise ao conteúdo de informação institucional deste universo, publicada nos respetivos sites, foi possível apurar que a esmagadora maioria das organizações não explicita publicamente o compromisso com a igualdade de género na missão e nos valores, e que apenas uma organização divulga o Plano para a Igualdade entre Mulheres e Homens em vigor. É também residual o número daquelas que divulga a atribuição do Prémio e/ou da Menção Honrosa.

Cerca de metade das organizações distinguidas participou no estudo através da resposta a um inquérito por questionário. Foi possível apurar que, na perceção da ampla maioria, a atribuição do PIQ estimulou a consolidação de políticas e práticas promotoras da igualdade entre mulheres e homens; no entanto, este não é um sentido de resposta unânime. Esta evidência encontra correspondência em todas as dimensões analisadas, expondo fragilidades no que diz respeito a: adoção de uma estratégia para a igualdade consubstanciada num plano de ação; integração da igualdade entre mulheres e homens nas ações de formação; adoção de medidas orientadas para a dessegregação horizontal e vertical; monitorização sistemática das remunerações das mulheres e dos homens para garantir que não exis- 
tem diferenciais injustificados; criação de mecanismos institucionalizados de informação e consulta de trabalhadores/as relacionados com questões de igualdade entre mulheres e homens, articulação entre a vida profissional, familiar e pessoal, e proteção da parentalidade; e adoção de procedimentos específicos para a apresentação e apreciação de queixas em casos de assédio sexual e/ou moral e de outras formas de violência de género no local de trabalho.

Os resultados obtidos sugerem que as práticas reconhecidas com a atribuição do PIQ não estavam plenamente ancoradas numa abordagem integrada de igualdade de género (gender mainstreaming). A evidente ausência de referência à igualdade entre mulheres e homens, no quadro da explicitação da missão e dos valores da esmagadora maioria das organizações premiadas, é demonstrativa da fragilidade dessa abordagem. Não se afigura também possível associar o reconhecimento público a um processo de transformação estrutural, orientado para a institucionalização de políticas, processos e práticas de promoção da igualdade entre mulheres e homens, num registo articulado, coerente e estabilizado no quotidiano das organizações.

Reconhece-se que a pesquisa aqui apresentada tem limitações. Além de não se ter conseguido reunir respostas de todo o universo de organizações distinguidas, não se nos afigurou possível mobilizar uma abordagem metodológica facilitadora de uma análise mais profunda e compreensiva. No entanto, tratando-se do primeiro estudo acerca do PIQ, os resultados vêm estimular uma reflexão académica, política e pública sobre os objetivos e o alcance do Prémio. Perante os resultados obtidos, afigura-se-nos relevante sugerir a atribuição muito criteriosa de um selo ou distintivo a organizações com práticas exemplares (em curso ou implementadas), necessariamente ancoradas numa abordagem efetiva de promoção da igualdade entre mulheres e homens. A distinção deverá carecer de renovação em cada quinquénio, em função da prestação de provas de manutenção/consolidação desse compromisso por parte das organizações distinguidas.

A presente investigação deixa em aberto várias questões em torno dos constrangimentos institucionais que se colocam à plena consecução de uma abordagem integrada de género. $\mathrm{O}$ presente trabalho expõe, aliás, a necessidade de um maior desenvolvimento do campo científico sobre género e organizações em Portugal.

\section{Referências bibliográficas}

Acker, Joan. 1990. «Hierarchies, jobs, bodies: a theory of gendered organizations.» Gender $\mathcal{E}$ Society 4 (2): 139-158. DOI: https:/ / doi.org /10.1177/089124390004002002.

Alvesson, Mats, e Yvonne Due Billing. 2009. Understanding gender in organizations. London: Sage.

Benschop, Yvonne, e Mieke Verloo. 2011. «Gender change, organizational change, and gender equality strategies.» In Handbook of Gender, Work \& Organization, organizado por Emma L. Jeannes, David Knights, e Patricia Y. Martin, 277-290. John Wiley \& Sons. 
Bendl, Regine. 2005. Revisiting Organization Theory - Integration and Deconstruction of Gender and Transformation of Organization Theory. Berlin: Peter Lang.

Calás, Marta B., Linda Smircich, e Evangelina Holvino. 2014. «Theorizing gender and organizations.» In The Oxford Handbook of Gender in Organizations, organizado por Savita Kumra, Ruth Simpson, e Ronald J. Burke, 17-52. Oxford: Oxford University Press.

Casaca, Sara Falcão, Heloísa Perista, Anália Torres, Catarina Correia, Eudelina Quintal, e Patrícia São João. 2016. Guia para a Promoção da Igualdade entre Mulheres e Homens. Lisboa: CIG. Disponível em http:/ / cite.gov.pt/pt/destaques/noticia506.html.

Casaca, Sara Falcão, e Johanne Lortie. 2018. Género e Mudança Organizacional. Turim: Centro Internacional de Formação da OIT. Disponível em: https:/ /www.ilo.org/lisbon/ publica\%C3\%A7\%C3\%B5es/WCMS_682648/lang--pt/index.htm.

Cockburn, Cynthia. 1991. In the Way of Women - Men's resistance to sex equality in Organizations. London: Macmillan.

Conselho da Europa. 1998. Gender Mainstreaming. Conceptual Framework, Methodology and Presentation of Good Practices. Strasbourg: Council of Europe. Disponível em: https: / / www.unhcr.org/3c160b06a.pdf.

Connell, Raewyn. 2006. «Glass ceilings or gendered institutions? Mapping the gender regimes of public sector worksites.» Public Administration Review 66 (6): 837-849. JSTOR: https: / / www.jstor.org/stable/4096601.

Correll, Shelley. 2017. «Reducing gender biases in modern workplaces: a small wins approach to organizational change.» Gender $\mathcal{E}$ Society 31 (6): 725-750. DOI: https:/ / doi.org/10.1177/0891243217738518.

EIGE - Instituto Europeu para a Igualdade de Género. 2016. Institutional Transformation Gender Mainstreaming Toolkit. Disponível em: https: / / eige.europa.eu/publications / institutional-transformation-gender-mainstreaming-toolkit.

Ely, Robin J., e Debra Meyerson. 2000. «Theories of gender in organizations: a new approach to organizational analysis and change.» Research in Organizatinal Behaviour 22: 103-151. DOI: https: / / doi.org/10.1016/S0191-3085(00)22004-2.

Eriksson-Zetterquist, Ulla, e David Renemark. 2016. "Can changes to gender equality be sustained?» Gender, Work E Organization 23 (4):363-378. DOI: https: / / doi.org / 10.1111/ gwao.12127.

Ferguson, Kathy. 1984. The Feminist Case against Bureaucracy. Philadelphia, PA: Temple University Press.

Ferreira, Virgínia. 1999. «Os paradoxos da situação das mulheres em Portugal.» Revista Crítica de Ciências Sociais 52-53: 199-227. Disponível em: https://ces.uc.pt/rccs/index. php?id=676.

Hearn, Jeff. 2000. «On the complexity of feminist interventions in organizations.» Organization 7 (4): 609-624. DOI: https:/ / doi.org/10.1177/135050840074006.

Kolb, Deborah, Joyce K. Fletcher, Debra E. Meyerson, Deborah Merrill-Sands, e Robin J. Ely. 2003. «Making change: a framework for promoting gender equity in organizations.» In Reader in Gender, Work and Organization, organizado por Robin J. Ely, Erica G. Foldy, Maureen A. Scully, e The Center for Gender in Organizations Simmons School, 10-25. Oxford: Blackwell Publishing.

Kotter, John P. e Cohen, Dan S. 2002. The Heart of Change: Real-life Stories of How People Change Their Organizations, Boston, MA: Harvard Business School Press.

Lewis, Patricia e Simpson, Ruth. 2012. «Kanter revisited: gender, power and (in)visibility.» International Journal of Management Review 14 (2): 141-158. DOI: https: / / doi.org/10.11 $11 / \mathrm{j} .1468-2370.2011 .00327$. 
Liff, Sonia; Cameron, Ivy. 1997. «Changing equality cultures to move beyond 'women's problems.» Gender, Work E Organization 4 (1): 35-46. DOI: https: / / doi.org/10.1111/ 14 68-0432.00022.

Macdonald, Mandy, Ellen Sprenger, e Irene Dubel. 1997. Gender and Organizational Change: Bridging the Gap between Policy and Practice. Amsterdam: Royal Tropical Institute.

Monteiro, Rosa, e Virgínia Ferreira. 2013. «Planos para a igualdade género nas organizações: Contributos para o desenho e realização dos diagnósticos organizacionais.» Sociedade e Trabalho 43-44-45: 123-136. Disponível em: http:/ / hdl.handle.net/10316/ 43897.

OIT - Organização Internacional do Trabalho. 2012. A Manual for Gender Audit Facilitators: The ILO Participatory Gender Audit Methodology. 2nd ed. Genève: International Labour Organization. Disponível em: https://www.ilo.org/wcmsp5/groups/public/---dgreports /---gender/documents/publication/wcms_187411.pdf.

Perista, Heloísa, Maria das Dores Guerreiro, Clara Jesus, e Maria Luísa Moreno. 2008. «A igualdade de género no quadro da responsabilidade social - o projecto EQUAL, diálogo social e igualdade nas empresas.» ex aequo 18: 103-120. Disponível em: http:/ / hdl.handle.net / $10071 / 13526$.

Rêgo, Maria do Céu da Cunha. 2012. «Políticas de igualdade de género na União Europeia e em Portugal: Influências e incoerências.» ex aequo 25: 29-44. Disponível em: http:/ / www.scielo.mec.pt/scielo.php?script=sci_arttext\&pid=S0874-55602012000100004.

Savage, Mike e Anne Witz (eds.). 1993. Gender and Bureaucracy. Oxford: Blackwell.

Walby, Sylvia. 1990. Theorizing Patriarchy. Oxford: Basil Blackwell.

Weick, Karl E., e Robert E. Quinn. 1999. «Organizational Change and Development.» Annual Review of Psychology 50: 361-386. DOI: https: / / doi.org/10.1146/ annurev.psych.50.1.361.

Witz, Anne. 1997. «Women's work». In Introducing Women's Studies: Feminist Theory and Practice, organizado por Victoria Robinson, e Diane Richardson, 239-257. London: Macmillan Education.

Mariana Pinheiro é socióloga e investigadora do Projeto Mulheres nos Órgãos de Gestão das Empresas: uma abordagem integrada (WoB), financiado pela Fundação para a Ciência e a Tecnologia, desenvolvido pelo Centro de Investigação em Sociologia Económica e das Organizações (SOCIUS), do Instituto Superior de Economia e Gestão, Universidade de Lisboa.

Endereço eletrónico: marianapinheiro@aln.iseg.ulisboa.pt

Sara Falcão Casaca é Professora Associada com Agregação do Instituto Superior de Economia e Gestão, Universidade de Lisboa, investigadora integrada do Centro de Investigação em Sociologia Económica e das Organizações (SOCIUS)/Consórcio em Ciências Sociais e Gestão (CSG), onde coordena a linha de investigação Trabalho, Emprego, Organizações e Género. É coordenadora do Programa de Doutoramento em Sociologia Económica e das Organizações.

Endereço eletrónico: sarafc@iseg.ulisboa.pt

Autora correspondente:

ISEG - Lisbon School of Economics \& Management

Universidade de Lisboa

Rua do Quelhas, n. ${ }^{\circ}$ 6, 1200-781 Lisboa - Portugal 
Anexo 1.

Lista das organizações distinguidas com o Prémio Igualdade É Qualidade

\begin{tabular}{|c|c|c|}
\hline Centro Hospitalar de Setúbal, E.P.E. & Menção Honrosa & $2016 / 2017$ \\
\hline $\begin{array}{l}\text { SIMAS, Oeiras e Amadora - Serviços Municipa- } \\
\text { lizados }\end{array}$ & Menção Honrosa & $2016 / 2017$ \\
\hline REN - Redes Energéticas Nacionais, SGPS, S.A. & Menção Honrosa & $2016 / 2017$ \\
\hline RENAULT Cacia, S.A. & Menção Honrosa & $2016 / 2017$ \\
\hline \multirow{2}{*}{$\begin{array}{l}\text { Associação DIANOVA Portugal - Intervenção } \\
\text { em Toxicodependências e Desenvolvimento } \\
\text { Social }\end{array}$} & Menção Honrosa & $2016 / 2017$ \\
\hline & Menção Honrosa & 2014 \\
\hline \multirow{2}{*}{$\begin{array}{l}\text { GEBALIS - Gestão do Arrendamento Social em } \\
\text { Bairros Municipais de Lisboa, E.M., S.A. }\end{array}$} & Menção Honrosa & 2014 \\
\hline & Menção Honrosa & 2010 \\
\hline AUCHAN Portugal Hipermercados, S.A. & Menção Honrosa & 2014 \\
\hline Banco Santander Totta & Prémio & 2012 \\
\hline \multirow{2}{*}{ Imprensa Nacional - Casa da Moeda } & Prémio & 2000 \\
\hline & Menção Honrosa & 2012 \\
\hline Ciclo Fapril - Indústrias Metalúrgicas, S.A. & Menção Honrosa & 2010 \\
\hline \multirow{2}{*}{$\begin{array}{l}\text { Espaço t - Associação para Apoio à Integração } \\
\text { Social e Comunitária }\end{array}$} & Menção Honrosa & $2002,2004,2010$ \\
\hline & Prémio & $2005-2006$ \\
\hline $\begin{array}{l}\text { Nova Gráfica de Amaral Rodrigues Resendes \& } \\
\text { Medeiros, Lda }\end{array}$ & Menção Honrosa & 2008-2009, 2010 \\
\hline $\begin{array}{l}\text { Serviços Municipalizados de Águas e Saneamen- } \\
\text { to da Câmara Municipal de Loures }\end{array}$ & Menção Honrosa & 2001, 2008-2009, 2010 \\
\hline AXA Seguros Portugal, S.A & Prémio & 2005-2006, 2008-2009 \\
\hline IKEA Portugal - Moveis e Decoração, Lda. & Prémio & 2008-2009 \\
\hline Metalomecânica Vítor Monteiro, Lda. & Menção Honrosa & 2008-2009 \\
\hline ORACLE Portugal, Sistemas de Informação, Lda. & Menção Honrosa & $2004,2007,2008-2009$ \\
\hline \multirow{2}{*}{ Companhia Portuguesa de Hipermercados, S.A. } & Prémio & 2007 \\
\hline & Menção Honrosa & $2005-2006$ \\
\hline \multirow{2}{*}{ Nestlé Portugal, S.A. } & Prémio & 2007 \\
\hline & Menção Honrosa & 2002 \\
\hline Grafe Publicidade, Lda. & Menção Honrosa & 2001, 2003, 2007 \\
\hline TAP Portugal, S.A. & Menção Honrosa & 2000,2007 \\
\hline $\begin{array}{l}\text { Xerox Portugal - Equipamentos de Escritório, } \\
\text { Lda. }\end{array}$ & Prémio & 2007,2000 \\
\hline Somague Engenharia, S.A. & Menção Honrosa & 2005-2006 \\
\hline Caixa Económica Montepio Geral & Prémio & 2000,2004 \\
\hline
\end{tabular}


E RECONHECIMENTO PÚBLICO

\begin{tabular}{lll}
\hline Companhia IBM Portuguesa & Prémio & 2004 \\
\hline $\begin{array}{l}\text { Friedrich Grohe Portugal, Componentes Sanitá- } \\
\text { rios, Lda. }\end{array}$ & Prémio & 2003 \\
\hline Luízes Representações, Lda. & Menção Honrosa & 2003 \\
\hline $\begin{array}{l}\text { ADE - Associação para o Desenvolvimento e } \\
\text { Emprego }\end{array}$ & Menção Honrosa & 2003 \\
\hline $\begin{array}{l}\text { Caixa de Crédito Agrícola Mútuo de Mafra, } \\
\text { C.R.L. }\end{array}$ & Prémio & 2002 \\
\hline Texto Editora, Lda. & Prémio & 2002 \\
\hline Opel Portugal, Comércio e Indústria, S.A. & Prémio & 2001 \\
\hline $\begin{array}{l}\text { Cooperativa Agrícola de Reguengos de Monsa- } \\
\text { raz }\end{array}$ & Menção Honrosa & 2001 \\
\hline $\begin{array}{l}\text { EBAHL - Equipamentos Bairros Históricos de } \\
\text { Lisboa, E.M. }\end{array}$ & Menção Honrosa & 2001 \\
\hline Farmácia Barreiros & Menção Honrosa & 2001 \\
\hline RES - Prestação de Serviços Comerciais, S.A. & Menção Honrosa & 2001 \\
\hline Bruno Janz & Prémio & 2000 \\
\hline Heska (Atualmente Lisgráfica) & Prémio & 2000 \\
\hline Salvador Caetano & Prémio & 2000 \\
\hline A. Silva Matos Metalomecânica, S.A. & Menção Honrosa & 2000 \\
\hline RTP - Radio Televisão Portuguesa, S.A. & Menção Honrosa & 2000 \\
\hline $\begin{array}{l}\text { Tavares de Oliveira - Assessores e Consultores } \\
\text { de Empresas, Lda. }\end{array}$ & Menção Honrosa & 2000 \\
\hline Por E E & & \\
\hline
\end{tabular}

Fonte: Elaboração própria 
